\title{
Development and validation of LC/MS/MS method for the simultaneous determination of montelukast, gliclazide, and nifedipine and its application to a pharmacokinetic study
}

\author{
Essam Ezzeldin ${ }^{1,2^{*}}$, Nisreen F Abo-Talib², Marwa H Tammam² and Abdelaaty A Shahat ${ }^{3}$
}

\begin{abstract}
Background: Montelukast is a leukotriene receptor antagonist for treatment of asthma, gliclazide is an oral hypoglycemic antidiabetic agent, and nifedipine is a calcium channel blocker used for treatment of angina pectoris and hypertension. These drugs may be prescribed to patients suffering from these chronic diseases. A survey of the literature reveals that there is no reported method for the simultaneous determination of montelukast, gliclazide, and nifedipine in pharmaceutical preparations or biological fluids.

Results: A simple, sensitive, and rapid method for the simultaneous quantification of montelukast, gliclazide, and nifedipine in human plasma was developed and validated. Montelukast, gliclazide, and nifedipine were resolved using rapid resolution LC/MS/MS Agilent system and SB-C $C_{18}(50 \times 4.6 \mathrm{~mm}) 1.8 \mu \mathrm{m}$ particle size column. The mobile phase consisted of acetonitrile: $0.1 \%$ formic acid (84:16). The three drugs were simultaneously extracted from plasma by protein precipitation with acetonitrile using zaferolukast as an internal standard. The method was validated according to FDA guidelines with good reproducibility and linearity of 0.999 and the limits of quantification were $0.11,0.04$, and $0.07 \mathrm{ng} / \mathrm{mL}$ for montelukast, gliclazide, and nifedipine, respectively. The accuracies of the three QCs for the three drugs were $99.48 \%$ (montelukast), 106.53\% (gliclazide), and 108.03\% (nifedipine) in human plasma. The validated method was applied to a pharmacokinetic study in human volunteers after oral administration of the three drugs. The applied LC/MS/MS method was shown to be sufficiently sensitive and suitable for pharmacokinetic studies.
\end{abstract}

Conclusion: The LC/MS/MS method was validated and successfully applied for the determination of montelukast, gliclazide, and nifedipine concentrations in human plasma.

\section{Background}

Montelukast, gliclazide, and nifedipine are drugs used for the management of chronic asthma and as prophylactic agents for exercise-induced asthma, treatment of non-insulin-dependent diabetes mellitus, and treatment of angina pectoris and hypertension, respectively.

This study aimed to determine serum concentrations of these three drugs, which are often jointly prescribed

\footnotetext{
* Correspondence: ezzeldin24@hotmail.com

'Drug Bioavailability Lab.College of Pharmacy, King Saud University, P.O. Box 2457, Riyadh 11451, Saudi Arabia

${ }^{2}$ Drug Bioavailability Center, National Organization for Drug Control and Research, P.O.Box 29, Cairo, Egypt

Full list of author information is available at the end of the article
}

to patients with chronic diseases such as asthma, hyperglycemia, and hypertension.

Montelukast sodium (MO), 1-[(\{(R)-m-[(E)-2-(7-chloro2-quinolyl)-vinyl]- $\alpha$-[o-(1-hydroxy-1-methylethyl) phenethyl]benzyl\}thio)methyl]cyclopropane acetate (Figure 1) is a selective leukotriene receptor antagonist for uses similar to those of zafirlukast, although it is reported to have a longer duration of action [1]. Gliclazide (GL), $N-(4-$ methylbenzenesulfonyl)- $N$ - (3-azabicyclo- [3.3.0] oct-3-) urea (Figure 1) is a second-generation sulfonylurea [2]. Nifedipine (NI), dimethyl-1,4-dihydro-2,6-dimethyl-4-(2nitrophenyl)pyridine-3,5-dicarboxylate, is a calcium channel blocker that inhibits the trans-membrane influx of
(D) Chemistry Central 
<smiles>CC(C)(O)c1ccccc1CC[C@H](SCC1(CC(=O)O)CC1)c1cccc(/C=C/c2ccc3ccc(Cl)cc3n2)c1</smiles>

Motelukast<smiles>Cc1ccc(S(=O)(=O)NC(=O)NN2CC3CCCC3C2)cc1</smiles><smiles>COC(=O)C1=C(C)NC(C)=C(C(=O)OC)C1c1ccccc1[N+](=O)[O-]</smiles>

Nifedipine

Figure 1 Chemical structures of montelukast, gliclazid and nifedipine.

$\mathrm{Ca}^{2+}$ into cardiac muscle cells and vascular smooth muscle through specific ion channels [3-5].

Several methods have been developed to quantitatively estimate MO concentration, including voltammetry [6], capillary electrophoresis [7], spectroflurometry [8], spectrophotometry [9], and liquid chromatography (LC) [10-19]. Some of these methods were developed to monitor pharmaceutical dosage forms [14-17] and drug concentrations in biological fluids $[8-13,18,19]$.

On the other hand, GL concentrations have been individually determined using spectrophotometry [20-22], radioimmunoassay [23], gas chromatography [24], HPLC [25-28], and mass spectroscopy [29,30]. In addition, GL concentrations have been determined in mixtures with metformin [31-34], metformin and pioglitazone [35], and rosiglitazone [36].

A detailed survey of the literature for NI revealed several reported methods for the assay of NI either alone or in combined drug formulations. These analytical techniques include spectrophotometry [37-42], HPLC [43-47], high performance thin layer chromatography [48], micellar electrokinetic chromatography [49], electroanalytical methods [50,51], flow injection analysis [52], and mass spectrometry $[53,54]$.

The present study aimed to develop a simple, sensitive, reproducible, and rapid LC/MS/MS method to monitor plasma levels of montelukast, gliclazide, and nifedipine for application in pharmacokinetic studies and routine clinical practice.

\section{Experimental}

\section{Chemicals and materials}

MO standard material ( $99.5 \%$ potency) and zaferolukast (ZA) (I.S.) (99.3\% potency) were kindly supplied by Merck. GL and NI standard material (99.22\% and 99.8\% potency, respectively) was kindly supplied by SigmaAldrich Co. (UK). Singulair $10 \mathrm{mg}$ tablets (MO) (Merk\&Co. Inc-USA), Diamicron $80 \mathrm{mg}$ tablets (GL) (Servier), and Epilat retard $20 \mathrm{mg}$ tablets (NI) by EPICO, Egypt.

Formic acid was purchased from Romil chemicals, England) and acetonitrile and methanol (HPLC grade) were purchased from, Alpha Chemicals, Egypt). Deionized water was obtained from a Milli-Q water purification system 3 (Millipore, France), and human plasma was supplied by VACSERA, Egypt). The mobile phase was filtered through a $0.45-\mu \mathrm{m}$ Whatman membrane filter.

\section{Instruments and chromatographic conditions}

An Agilent triple quadrupole mass spectrometer with an API source coupled with an Agilent pump controlled by an Agilent 1200 controller and equipped with an Agilent 1200 autosampler injector was used for analysis. Separation was performed using an analytical Agilent SB-C18 column $(50 \times 4.6 \mathrm{~mm})$ with particle size of $1.8 \mu \mathrm{m}$. The mobile phase consisting of acetonitrile: $0.1 \%$ formic acid (84:16), was delivered at a flow rate of $0.6 \mathrm{~mL} / \mathrm{min}$.

Mass spectra were obtained using an electrospray ionization source operated in the multiple reaction monitoring (MRM) mode. Sample introduction and ionization were both performed in the positive ion mode (MO, GL, and $\mathrm{NI}$ ) and negative ion mode (ZA). The cone voltage was set at $135 \mathrm{~V}$ for both $\mathrm{MO}$ and GL and $80 \mathrm{~V}$ and $150 \mathrm{~V}$ for NI and ZA, respectively. The capillary voltage was optimized at $4000 \mathrm{~V}$. Argon was used as the collision gas. The collision energy was set at 20, 15, 5, and $25 \mathrm{MeV}$ for $\mathrm{MO}, \mathrm{GL}, \mathrm{NI}$, and ZA, respectively. Optimal gas flow during tuning was $8 \mathrm{~L} / \mathrm{min}$ and nebulizer pressure was $30 \mathrm{psi}$. The source temperature was $325^{\circ} \mathrm{C}$. The selected mass 
transitions ion pairs were 586.2/568.3, 324.4/127.2, 347.3/ 315.2 at (positive ion) and 574.6/462.2 at (negative ion) for MO, GL, NI, and ZA (I.S.), respectively. Agilent Mass Hunter software was used for data acquisition. For quantification, the peak area ratios of the target ions of the drugs to those of the internal standard were compared with weighted (1/concentration $\left.{ }^{2}\right)$ least square calibration curves in which the peak area ratios of the calibration standards were plotted versus their concentrations.

\section{Preparation of stock solutions and calibration standards}

Stock solutions of each of the MO, GL, NI, and ZA (I.S.) samples were prepared in methanol at a concentration of $100.0 \mu \mathrm{g} / \mathrm{mL}$ and stored at $4^{\circ} \mathrm{C}$. Handling and analysis of all samples were performed under diffused light conditions (prepared away from light using opaque glasses and aluminum foil). Evaluations of the assay were performed by seven point calibration curves made by serial dilutions of the stock solution of each drug at the nominal concentration ranges of $10.0-800.0 \mathrm{ng} / \mathrm{mL}, 10.0-5000.0 \mathrm{ng} / \mathrm{mL}$, and $10.0-600.0 \mathrm{ng} / \mathrm{mL}$ for MO, GL, and NI, respectively, in human plasma. The slopes and intercepts of the calibration lines were determined.

\section{Sample preparation}

Sample preparation was performed by liquid-liquid extraction of $100 \mu \mathrm{L}$ of plasma by protein precipitation using $300 \mu \mathrm{L}$ of acetonitrile. A $5.0-\mu \mathrm{L}$ aliquot of the internal standard solution was added. The mixture was then shaked by vortex for $30 \mathrm{~s}$ and centrifuged for $10 \mathrm{~min}$ at $4000 \mathrm{rpm}$. A $20 \mu \mathrm{L}$ aliquot of the supernatant was injected into the LC/MS/MS instrument.

\section{Clinical protocol}

This method was applied for the analysis of plasma samples after the administration of a single dose of $10 \mathrm{mg}$ MO (Singulair tablets), $80 \mathrm{mg}$ GL (Diamicron tablets), and $20 \mathrm{mg}$ NI (Epilat retard tablets) to six healthy male volunteers. The study protocol was approved by the Ethics Committee of Bioavailability Studies (NODCAR). The age of the volunteers ranged from 29 to 39 years and the body weights of the subjects ranged from 58 to $71 \mathrm{~kg}$. All subjects provided written informed consent. The study was conducted in accordance with the provisions of the Declaration of Helsinki. After an overnight fast for $10 \mathrm{~h}$, all volunteers received a single dose of the three drugs with $200 \mathrm{~mL}$ of water. Blood samples $(3 \mathrm{~mL})$ from a suitable antecubital vein were collected into heparincoated tubes at 0.0 (before dose), 0.25, 0.5, 0.75, 1.0, 1.5, 2.0, 2.5, 3, 4, 6.0, 8.0, 10.0, 12.0, 24.0, and $48.0 \mathrm{~h}$ post dosing. The blood samples were centrifuged at $3000 \mathrm{rpm}$ for $5 \mathrm{~min}$ at room temperature and the plasma was removed and stored at $-80^{\circ} \mathrm{C}$ until assayed for $\mathrm{MO}, \mathrm{GL}$, and NI content. All samples from a single volunteer were analyzed in the same run in order to avoid inter-assay variations.

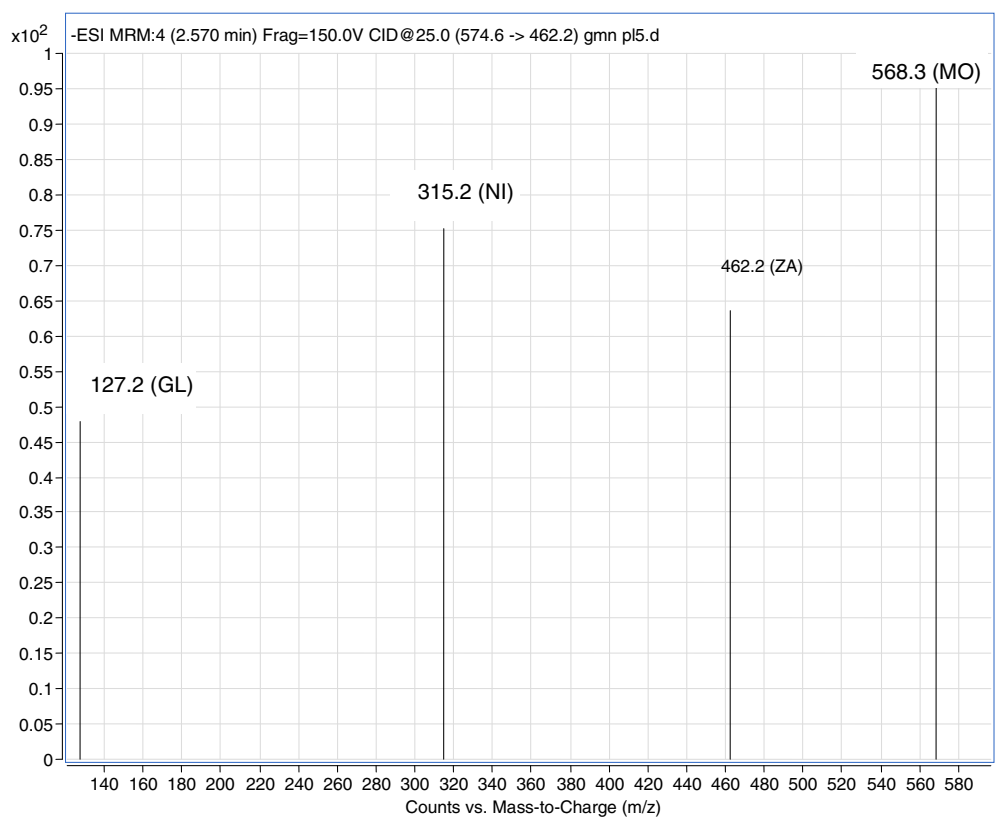

Figure 2 Mass spectra of the positive ion of montelukast (MO), gliclazide (GL), nifedipine (NI) and negative ion zaferolukast (ZA) internal standard. 


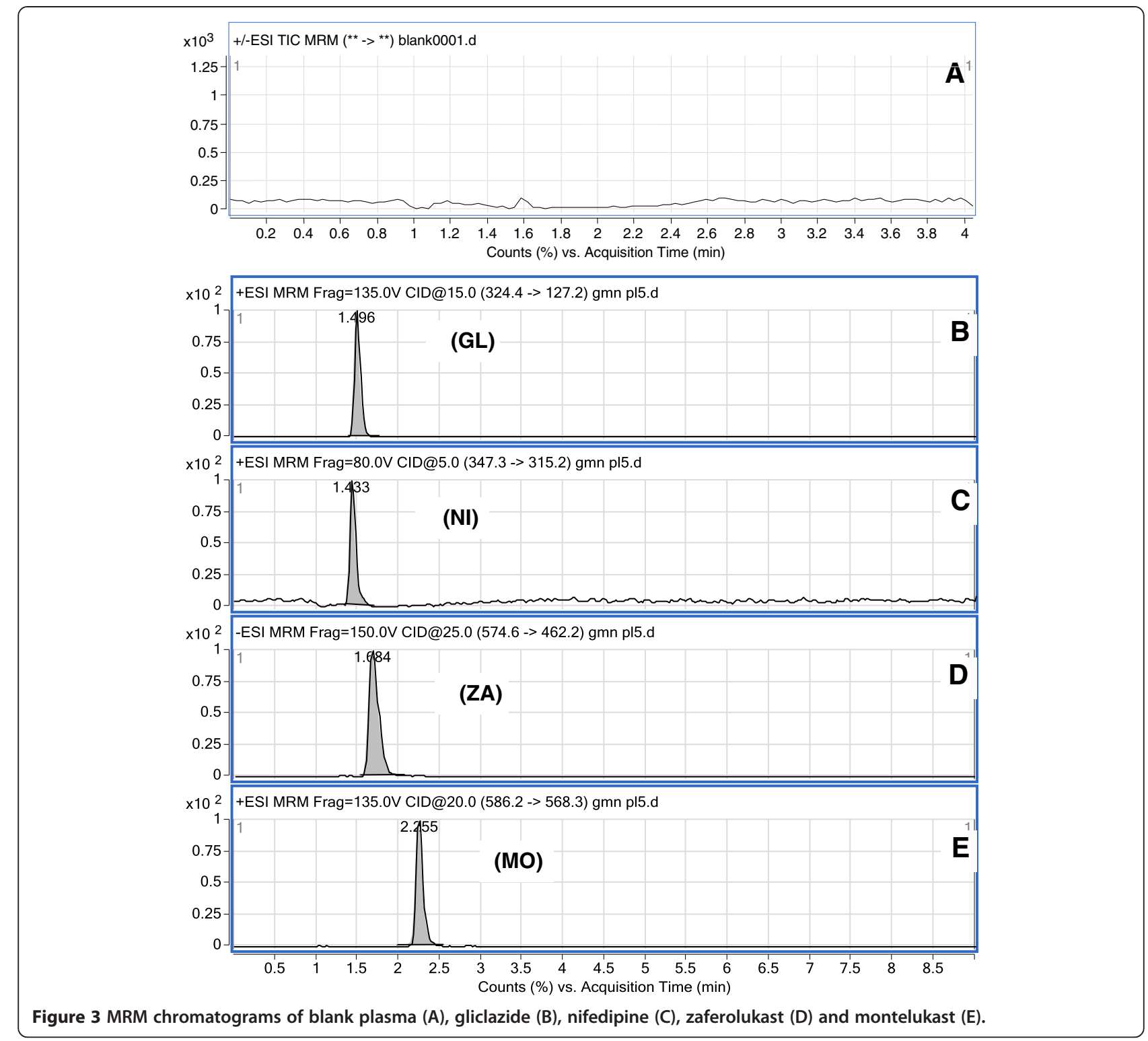

\section{Pharmacokinetic analysis}

Pharmacokinetic parameters from the human plasma samples were calculated by a noncompartmental model using the WinNonlin 5.3 software. Blood samples were taken for a period of $48 \mathrm{~h}$. and it was considered as the area under the concentration-time curve (AUC) ratios were higher than $80 \%$ as per FDA guidelines [55,56]. The first-order terminal elimination rate constant $\left(\mathrm{K}_{\mathrm{el}}\right)$ was estimated by linear regression from the points describing the elimination phase on a log-linear plot. The maximum observed plasma concentration $\left(\mathrm{C}_{\max }\right)$ and the time taken to achieve this maximum level $\left(t_{\max }\right)$ were directly obtained from the curves.

The areas under the time-concentration curve for $\mathrm{MO}, \mathrm{GL}$, and NI plasma concentration versus time for $48 \mathrm{~h}\left(\mathrm{AUC}_{0-48}\right)$ were calculated using the trapezoidal method. Extrapolation of this area to infinity $\left(\mathrm{AUC}_{0-\infty}\right)$ was performed by adding the value $\mathrm{C}_{48} / \mathrm{K}_{\mathrm{el}}$ to the calculated $\mathrm{AUC}_{0-48}$ where $\mathrm{C}_{48}$ is the $\mathrm{MO}, \mathrm{GL}$, and NI plasma concentration at $48 \mathrm{~h} . \mathrm{K}_{\mathrm{el}}$ is the first-order terminal elimination rate constant.

\section{Results and discussion}

New methods for simultaneous determination of two or more compounds without interference from each other are always of interest. The goal of this work was to develop and validate a simple, rapid, and sensitive LC/MS/MS assay method for simultaneous extraction and quantification of montelukast, gliclazide, and nifedipine in plasma and to apply this method in a pharmacokinetic study. To achieve these goals, during method development, different options were 
Table 1 Intra-day and inter-days precision and accuracy for determination of montelukast in spiked human plasma

\begin{tabular}{|c|c|c|c|c|c|c|c|c|c|c|c|c|c|c|}
\hline \multirow{3}{*}{ Parameters } & \multicolumn{14}{|c|}{ Theoretical concentration $(\mathrm{ng} / \mathrm{mL})$} \\
\hline & \multicolumn{7}{|c|}{ Intra-day reproducibility } & \multicolumn{7}{|c|}{ Inter-days reproducibility } \\
\hline & 10 & 20 & 40 & 80 & 120 & 400 & 800 & 10 & 20 & 40 & 80 & 120 & 400 & 800 \\
\hline \multicolumn{15}{|c|}{ Concentration found (ng/mL) } \\
\hline Mean & 10.93 & 19.9 & 38.5 & 77.43 & 109.16 & 372.45 & 808.55 & 10.37 & 18.92 & 37.95 & 78.23 & 105.58 & 392.03 & 816.69 \\
\hline Precision & 1.69 & 7.79 & 4.49 & 8.73 & 4.56 & 14.13 & 7.68 & 13.74 & 12.52 & 14.01 & 13.81 & 11.34 & 14.14 & 12.84 \\
\hline Accuracy (\%) & 109.32 & 99.5 & 96.24 & 96.79 & 109.16 & 93.11 & 101.07 & 103.66 & 94.59 & 94.89 & 97.79 & 105.58 & 98.01 & 102.09 \\
\hline
\end{tabular}

evaluated to optimize sample extraction, detection parameters, and chromatography.

\section{Method development}

LC conditions were optimized to obtain a short run time and adequate resolution between $\mathrm{MO}, \mathrm{GL}, \mathrm{NI}$, and the internal standard ZA. Several trials were performed to select an optimal ratio of acetonitrile to $0.1 \%$ formic acid. These trials determined that $86 \%$ acetonitrile ratio was optimal for simultaneous separation of the three drugs. Using this mobile phase delivered at a flow rate of $0.6 \mathrm{~mL} / \mathrm{min}$ resulted in improved signals when compared with different ratios of same reagents. In addition, MS parameters were optimized to obtain maximum sensitivity.

Electrospray ionization (ESI) was evaluated to obtain a better response from the analytes. The best signal was achieved using an ESI-positive ion mode for MO, GL, and NI, and negative ion mode for ZA. The product ion spectrum for MO, GL, NI, and ZA yielded a high abundance of fragment ions of $\mathrm{m} / \mathrm{z} 568.3,127.2,315.2$, and 462.2, respectively (Figure 2). The representative extracted ion chromatograms of the three drugs and the internal standard are shown in Figure 3.

\section{Method validation \\ Selectivity, linearity, limit of detection, and limit of quantitation}

The selectivity of the method was evaluated by comparing the chromatograms obtained from the MO, GL, and NI samples and the internal standard with those obtained from the blank samples. A representative chromatogram obtained from blank plasma is shown in Figure 3A. The chromatograms of the spiked plasma samples are shown in Figure 3B, C, D, and E. Under the optimized conditions, a linear relationship with a good correlation coefficient $(\mathrm{r}=0.999, \mathrm{n}=6)$ was observed between the peak area ratios and the concentrations of $\mathrm{MO}, \mathrm{GL}$, and $\mathrm{NI}$ in the range of 10.0-800.0, 10.0-5000.0, and 10.0-600.0 ng/mL, respectively. The experiments were performed using a standard seven-point series for each drug.

The limit of detection (LOD) and limit of quantitation (LOQ) were calculated according to the $\mathrm{ICH}$ guidelines for validation of analytical procedures based on the standard deviation of the response and the slope of the calibration curve [57] using the formula: LOD or LOQ $=\kappa \sigma / S$, where $\kappa=3.3$ for LOD and 10 for LOQ, $\sigma$ is the standard deviation of the response, and $\mathrm{S}$ is the slope of the calibration curve. Calculations of six replicate experimental injections determined LODs of 0.04, 0.01, and $0.02 \mathrm{ng} / \mathrm{mL}$ and LOQs of $0.11,0.04$, and $0.07 \mathrm{ng} / \mathrm{mL}$ for MO, GL, and NI, respectively.

\section{Accuracy and precision}

The accuracy and precision of the proposed method were determined by intra-day and inter-day replicate analyses of plasma spiked with different concentrations of each drug covering the working linear ranges. The inter-day assays were carried out on three different days with the same concentration levels for spiked plasma samples. The accuracy values from the intraday analysis were $94.59 \%-105.58 \%, 89.75 \%-114.86 \%$, and $83.46 \%-110.22 \%$, whereas the values for the interday analysis were $93.11 \%,-109.32 \%, 99.93 \%-106.16 \%$, and $97.90 \%-114.82 \%$ for MO (Table 1), GL (Table 2), and NI (Table 3), respectively, indicating the accuracy and

Table 2 Intra-day and inter-days precision and accuracy for determination of gliclazide in spiked human plasma

\begin{tabular}{|c|c|c|c|c|c|c|c|c|c|c|c|c|c|c|}
\hline \multirow{3}{*}{ Parameters } & \multicolumn{14}{|c|}{ Theoretical concentration $(\mathrm{ng} / \mathrm{mL})$} \\
\hline & \multicolumn{7}{|c|}{ Intra-day reproducibility } & \multicolumn{7}{|c|}{ Inter-days reproducibility } \\
\hline & 10 & 20 & 100 & 250 & 500 & 1000 & 5000 & 10 & 20 & 100 & 250 & 500 & 1000 & 5000 \\
\hline \multicolumn{15}{|c|}{ Concentration found (ng/mL) } \\
\hline Mean & 11.49 & 18.5 & 89.75 & 241.79 & 512.61 & 1045.04 & 4767.74 & 10.27 & 19.99 & 106.16 & 261.21 & 527.12 & 1037.07 & 5215.71 \\
\hline Precision & 7.35 & 11.1 & 13.49 & 11.42 & 5.33 & 0.6 & 10.92 & 15.54 & 15.17 & 15.39 & 14.92 & 4.17 & 3.22 & 10.49 \\
\hline Accuracy (\%) & 114.86 & 92.5 & 89.75 & 96.72 & 102.52 & 104.5 & 95.35 & 102.68 & 99.93 & 106.16 & 104.48 & 105.42 & 103.71 & 104.31 \\
\hline
\end{tabular}


Table 3 Intra-day and inter-days precision and accuracy for determination of nifedipine in spiked human plasma

\begin{tabular}{|c|c|c|c|c|c|c|c|c|c|c|c|c|c|c|}
\hline \multirow{3}{*}{ Parameters } & \multicolumn{14}{|c|}{ Theoretical concentration $(\mathrm{ng} / \mathrm{mL})$} \\
\hline & \multicolumn{7}{|c|}{ Intra-day reproducibility } & \multicolumn{7}{|c|}{ Inter-days reproducibility } \\
\hline & 10 & 20 & 40 & 80 & 100 & 200 & 600 & 10 & 20 & 40 & 80 & 100 & 200 & 600 \\
\hline \multicolumn{15}{|c|}{ Concentration found (ng/mL) } \\
\hline Mean & 8.35 & 21.33 & 44.09 & 83.93 & 101.1 & 203.63 & 634.48 & 10.51 & 20.01 & 39.16 & 91.17 & 114.82 & 227.41 & 664.38 \\
\hline Precision & 4.21 & 10.55 & 6.69 & 8.09 & 4.2 & 2.76 & 1.45 & 8.84 & 5.7 & 15.54 & 14.52 & 4.86 & 1.82 & 2.47 \\
\hline Accuracy (\%) & 83.46 & 106.67 & 110.22 & 104.91 & 101.1 & 101.82 & 105.75 & 105.08 & 100.04 & 97.9 & 113.96 & 114.82 & 113.7 & 110.73 \\
\hline
\end{tabular}

precision of the proposed method. The volunteer samples that had greater concentrations compared with the highest concentration in the validation were diluted before injection and the actual concentrations were recalculated.

\section{Application to pharmacokinetic study}

The method described here was successfully applied to a pharmacokinetic study of MO, GL, and NI in plasma samples from healthy human volunteers. None of the volunteers exhibited any general adverse reactions. Following oral drug administration, plasma concentrationtime profiles of the three drugs best fit a noncompartment in all subjects. A representative MRM chromatogram of a plasma sample extracted from a healthy volunteer at $6 \mathrm{~h}$ is shown in Figure 4. A representative plasma concentration-time profile is shown in

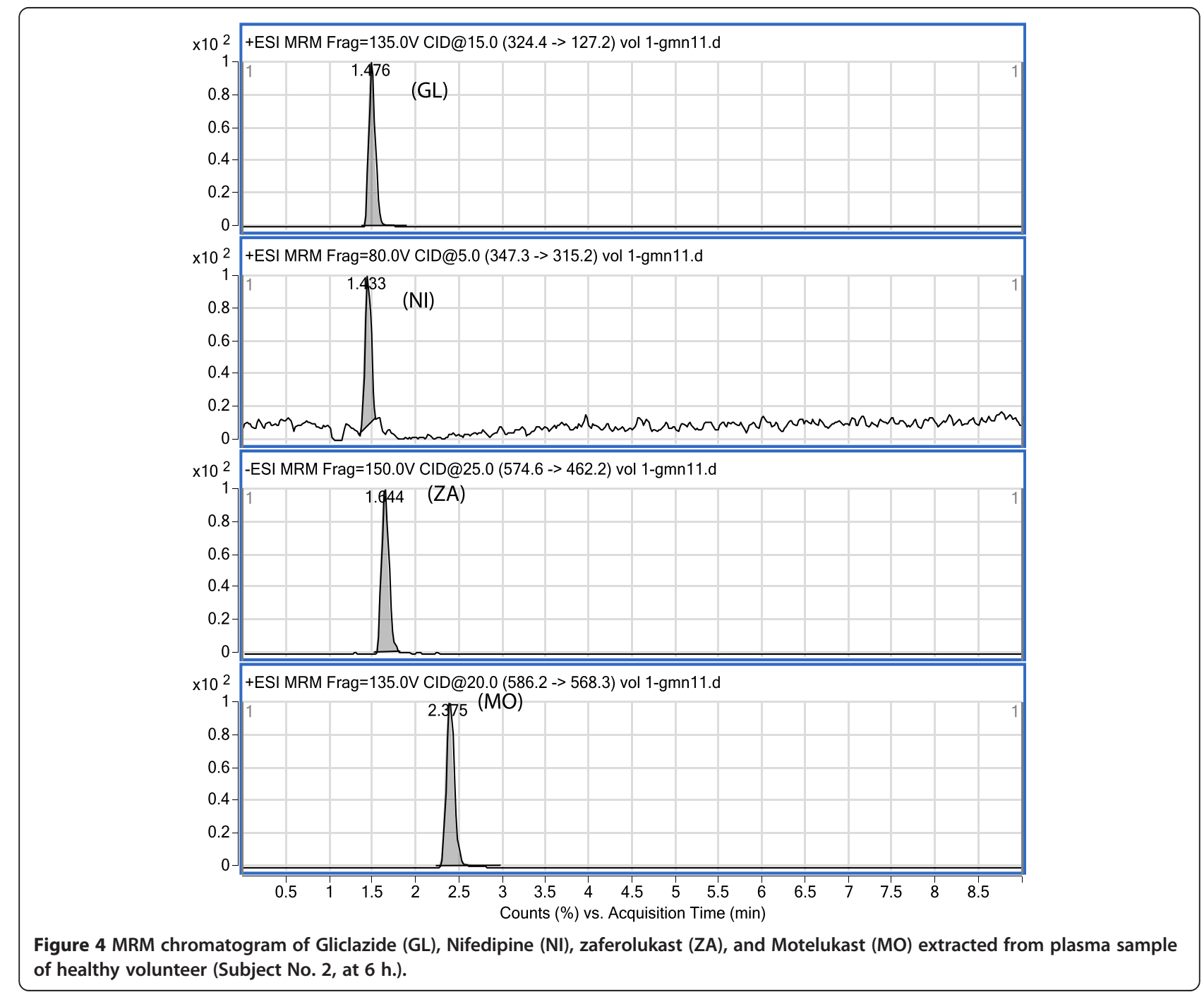



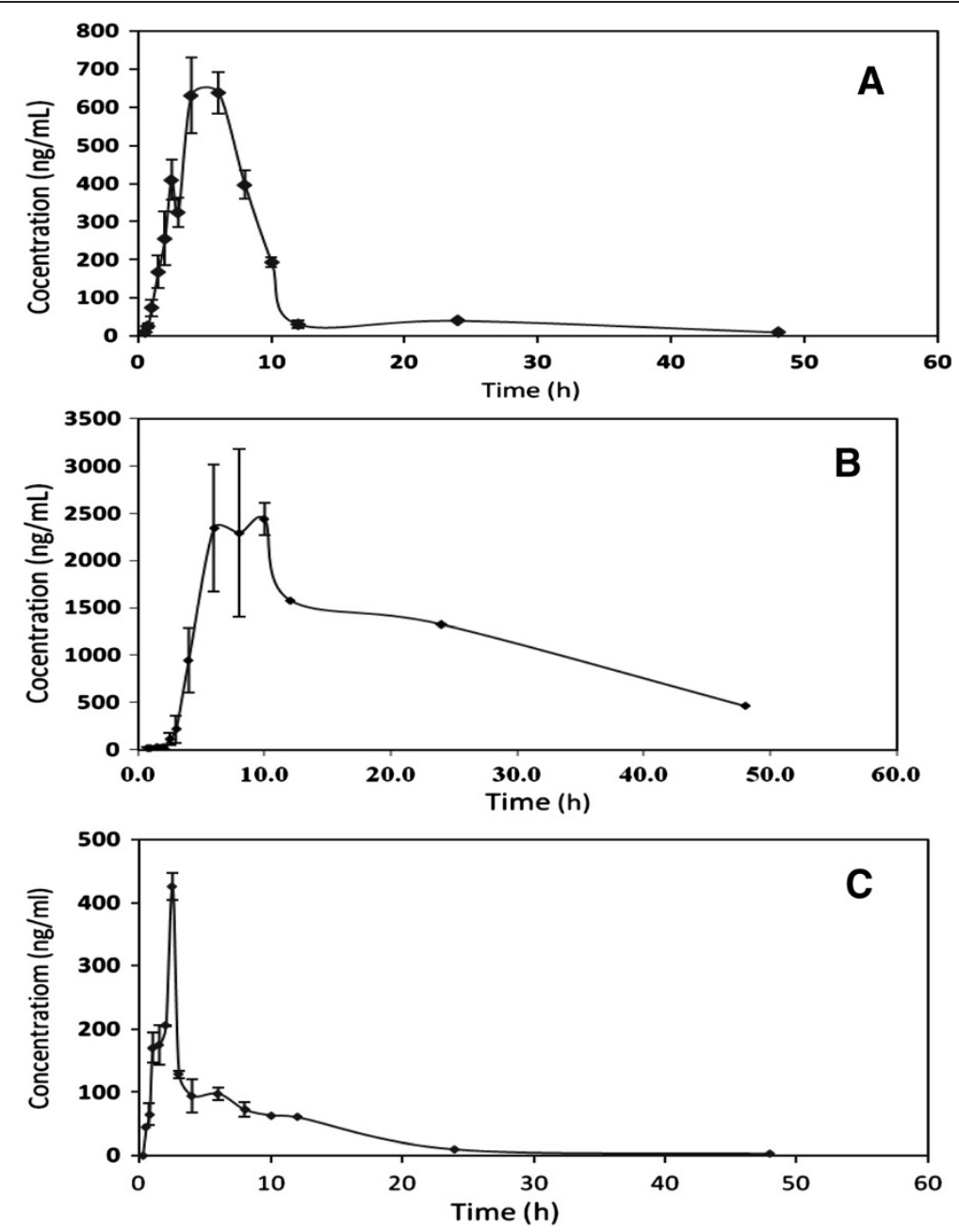

Figure 5 Mean $( \pm S D)$ Plasma Concentration versus time of montelukast $(A)$, gliclazide $(B)$ and nifedipine $(C)$ following simultaneous administration of montelukast $(10 \mathrm{mg})$, gliclazide $(80 \mathrm{mg})$ and nifedipine $(20 \mathrm{mg})$ Tablets to six healthy male volunteers.

Figure 5. The estimated pharmacokinetic parameters are shown in Table 4.

\section{Conclusions}

The results of this study showed that the validated LC/MS/MS method proved to be a simple, rapid, reliable, selective, and sensitive method sufficient for simultaneous monitoring of pharmacokinetic parameters of montelukast, gliclazide, and nifedipine. A small plasma sample volume and LOQ were sufficiently sensitive to detect terminal phase concentrations of the drugs.

Table 4 Pharmacokinetic Parameters required for assessment of Montelukast, Gliclazide and Nifedipine Bioavailability

\begin{tabular}{|c|c|c|c|}
\hline Parameters & Montelukast & Gliclazide & Nifedipine \\
\hline$C_{\max }(\mathrm{ng} / \mathrm{mL})$ & $882.39 \pm 245.8$ & $2917.2 \pm 991.3$ & $353.519 \pm 104.5$ \\
\hline$A \cup C_{0-48}(\mathrm{ng} \cdot \mathrm{h} / \mathrm{mL})$ & $4493.23 \pm 2576.3$ & $45156.15 \pm 45988.13$ & $1261.81 \pm 155.1$ \\
\hline $\mathrm{AUC}_{0-a}(\mathrm{ng} . \mathrm{h} / \mathrm{ml})$ & $4797.49 \pm 2808.6$ & $49915.8 \pm 51881.3$ & $1423.3 \pm 295.5$ \\
\hline $\mathrm{t}_{\max }$ (median) $\mathrm{h}$ & 4.25 & 8.00 & 4.24 \\
\hline$t_{1 / 2}(h)$ & $3.86 \pm 27$ & $7.24 \pm 8.3$ & $2.7 \pm 0.36$ \\
\hline MRT (h) & $7.27 \pm 3.7$ & $15.46 \pm 11.6$ & $5.88 \pm 3.1$ \\
\hline $\mathrm{K}_{\mathrm{el}}(\mathrm{h})$ & $0.282 \pm 0.32$ & $0.240 \pm 0.17$ & $0.255 \pm 0.03$ \\
\hline
\end{tabular}




\section{Abbreviations}

MO: Montelukast sodium; GL: Gliclazide; NI: Nifedipine; LC/MS/MS: Liquid chromatography/Mass/Mass spectrometry; LOD: Limit of detection; LOQ: Limit of quantification; I.S: Internal standard.

\section{Competing interests}

The authors declare that they have no competing interests.

\section{Authors' contributions}

EE proposed the subject, designed the study, conducted pharmacokinetic and statistical analysis, participated in the results discussion and revised manuscript. NFA participated in study design, assay design, literature review, conducted the validation of the assay, analysis of the samples, participated in the results discussion and participated in preparing the manuscript. MHT participated in study design, assay design, literature review, conducted the validation of the assay, analysis of the samples, participated in the results discussion and participated in preparing the manuscript. AAA participated in the writing the manuscript. All authors read and approved the final manuscript

\section{Acknowledgment}

The authors extend their appreciation to the Deanship of Scientific Research at King Saud University for funding the work through the research group project No. RGP-VPP-262

\section{Author details}

'Drug Bioavailability Lab.College of Pharmacy, King Saud University, P.O. Box 2457, Riyadh 11451, Saudi Arabia. ${ }^{2}$ Drug Bioavailability Center, National Organization for Drug Control and Research, P.O.Box 29, Cairo, Egypt. ${ }^{3}$ Department of Pharmacognosy, College of Pharmacy, King Saud University, P.O. Box 2457, Riyadh 11451, Saudi Arabia.

Received: 27 October 2013 Accepted: 4 March 2014 Published: 11 March 2014

\section{References}

1. García-Marcos L, Schuster A, Pérez-Yarza EG: Benefit-risk assessment of antileukotrienes in the management of asthma. Drug Saf 2003, 26:483-518

2. Palmer KJ, Brogden N: Gliclazide an update of its pharmacological properties and therapeutic efficacy in non-insulin-dependent diabetes mellitus. Drugs 1993, 46:92-125.

3. Miller RJ: Multiple calcium channels and neuronal function. Science 1987, 235:46-52.

4. Murdoch D, Brogden RN: Sustained release nifedipine formulations: an appraisal of their current uses and prospective roles in the treatment of hypertension, ischaemic heart disease and peripheral vascular disorders. Drugs 1993, 41:737-779.

5. Weetman SC: Martindale The Extra Pharmacopoeia. 33rd edition. London: Royal Pharmaceutical Society; 2002:940-946.

6. Alsarra I, Al-Omar M, Gadkariem EA, Belal F: Voltammetric determination of montelukast sodium in dosage forms and human plasma. Farmaco 2005, 60:563-567.

7. Shakalisava Y, Regan F: Determination of montelukast sodium by capillary electrophoresis. J Sep Sci 2008, 31:1137-1143.

8. Alsarra I, Khalil NY, Sultan M, Al-Ashban R, Belal F: Spectrofluorometric determination of montelukast in dosage forms and spiked human plasma. Pharmazie 2005, 60:823-826.

9. Saeed Arayne M, Sultana N, Hussain F: Spectrophotometric method for quantitative determination of montelukast in bulk, pharmaceutical formulations and human serum. J Anal Chem 2009, 64:690-695.

10. Bharathi DV, Hotha KK, Jagadeesh B, Mullangi R, Naidu A: Quantification of montelukast, selective cysteinyl leukotriene receptor (CysLT1) antagonist In human plasma by liquid chromatography- mass spectrometryvalidation and its application to a human pharmacokinetic study. Biomed Chromatogr 2009, 23:804-810.

11. Sripalakit $P$, Kongthong B, Saraphanchotiwitthaya A: A simple bioanalytical assay for determination of montelukast in human plasma- application to a pharmacokinetic study. J Chromatogr B Analyt Technol Biomed Life Sci 2008, 869:38-44.
12. Smith GA, Rawls CM, Kunka RL: An automated method for the determination of montelukast in human plasma using dual-column HPLC analysis and peak height summation of the parent compound and its photo degradation product. Pharm Res 2004, 21:1539-1544.

13. Papp R, Luk P, Mullett WM, Kwong E: A rapid and sensitive method for the quantitation of montelukast in sheep plasma using liquid chromatography/tandem mass spectrometry. J Chromatogr B Analyt Technol Biomed Life Sci 2007, 858:282-286.

14. Saravanan M, Siva Kumari K, Pratap Reddy P, Naidu MN, Moses Babu J, Srivastava AK, Lakshmi Kumar T, Chandra Sekhar BV, Satyanarayana B: Identification, synthesis, isolation and spectral characterization of potential impurities of montelukast sodium. J Pharm Biomed Anal 2008, 48:708-715.

15. Al Omari MM, Zoubi RM, Hasan El, Khader TZ, Badwan AA: Effect of light and heat on the stability of montelukast in solution and in its solid state. J Pharm Biomed Anal 2007, 45:465-471.

16. Hoang TH, Sharma R, Susanto D, Di Maso M, Kwong E: Microwave-assisted extraction of active pharmaceutical ingredient from solid dosage forms. J Chromatogr A 2007, 1156:149-153.

17. Prashanth Kumar K, Akiful Haque M, Pradeep Kumar T, Nivedita G, Hasan Amrohi S, Prasad W, Prakash VD: Simultaneous determination of Montelukast sodium and fexofenadine hydrochloride in combined dosage form by using RP-HPLC method. World J Chem 2012, 7(2):42-46.

18. Balasekhara RC, Bahlul ZA, Babu RC, Mukkanti K, Chandrasekhar BK: Method development and validation of Montelukast in human plasma by HPLC coupled with ESI-MS/MS: application to a bioequivalence study. Sci Pharm 2010, 78:411-422.

19. Alireza S, Afshin Z, Seyed MF, Arash K, Babak M: Rapid and sensitive determination of Montelukast in human plasma by high performance liquid chromatographic method using monolithic column: application to pharmacokinetic studies. J Bioequiv Availab 2010, 2:135-138.

20. Revathi R, Saravanan VS, Mohan Raj P, Ethiraj T, Ganesan V: Spectrophotometric Estimination of Gliclazide in Bulk and Pharmaceutical Dosage Forms. Int Res J Pharm 2010, 1:277-281.

21. Samina AJ, Snehal PM, Poonam SK, Yogesh VP, Kishor BB: Development and validation of UV spectrophotometric method for the determination of Gliclazide in tablet dosage form. Der Pharma Chemica 2011, 3:338-343.

22. Pinderjit S, Rajnish K, Harinder S: Application of UV spectrophotometric method for analysis of gliclazide in pharmaceutical dosage forms. Int J Pharm Pharm Sci 2011, 3:259-260

23. Suzuki H, Miki M, Sekine $Y$, Kagemoto A, Negoro T, Maeda T, Hashimoto M: Determination of new hypoglycaemic drug Gliclazide in human serum by radio immunoassay. J Pharmacobiodyn, 4(3):217-225.

24. Maeda T, Yamaguchi T, Hashimoto M: Gas chromatographic determination of the hypoglycaemic agent gliclazide in plasma. J Chromatogr B Biomed Sci Appl 1981, 223:357-363.

25. Kuo CY, Wu SM: High-performance liquid chromatography with electrochemical detection for analysis of gliclazide in plasma. $J$ Chromatogr A 2005, 1088:131-135.

26. Damanjeet G, Lakshmi GG: HPLC method for determination of Gliclazide in human serum. Asian j Chem 2009, 21:4258-4264.

27. Park JY, Kim KA, Kim SL, Park PW: Quantification of gliclazide by semi-micro high-performance liquid chromatography: application to a bioequivalence study of two formulations in healthy subjects. J Pharm Biomed Anal 2004, 35:943-949.

28. Jia-Feng Y: Determination of Gliclazide in human plasma by high performance liquid chromatography. Asian J Drug Metab Pharmacokinet 2004, 4:231-234

29. Maurer HH, Kratzsch C, Kraemer T, Peters FT, Weber AA: Screening, libraryassisted identification and validated quantification of oral antidiabetics of the sulfonylurea-type in plasma by atmospheric pressure chemical ionization liquid chromatography-mass spectrometry. J Chromatogr $B$ Anal Technol Biomed Life Sci 2002, 773:63-73.

30. Wang CY, Zhang W, Xiang BR, Yu LY, Ma PC: Liquid chromatography mass spectrometry method for the determination of gliclazide in human plasma and application to a pharmacokinetic study of gliclazide sustained release tablets. Arzneimittelforschung 2008, 58(12):653-658.

31. Ediga V, Krishna R, Chandra KS: A new simple RP-HPLC method for simultaneous estimation of Metformin $\mathrm{Hcl}$ and Gliclazide tablet dosage form. Int J Pharm Bio Sci 2012, 4:277-283.

32. Kanij F, Md Zakir R, Tasnuva H, Mohammad Abul Kalam A, Md Selim R: Development and validation of a simple method for simultaneous 
estimation of Metformin hydrochloride and gliclazide in tablets by using RP-HPLC. Dhaka Univ J. Pharm Sci 2010, 9:83-89.

33. Dhabale PN, Seervi CR: Simultaneous UV spectrophotometric method for estimation of gliclazide and metformine hydrochloride in tablet dosage form. Int J Chem Tech Res 2010, 2:813-817.

34. Ketan PD, Parthika AN, Yadvendra KA: Development and validation of spectrophotometric method for simultaneous estimation of gliclazide and metformin hydrochloride in bulk and tablet dosage form by simultaneous equation method. Int J Pharm Sci Res 2011, 2:1559-1563.

35. Nazar Mustafa M, Anurekha J: Simultaneous estimation of metformin hydrochloride, pioglitazone hydrochloride and gliclazide by validated rp-hplc method in solid dosage form. Int J Pharm Pharm Sci 2012, 4:72-76.

36. Rathinavel G, Umanath U, JValaramathy J, Samuel Joshua L, Selvin Thanuja C, Ganesh M, Shivkumar T, Priyadarsini R: RP-HPLC method for simultaneous estimation of rosiglitazone and gliclazide in tablets. EJ chem 2009, 6(4):1188-1192.

37. Kasture AV, Ramteke M: Simultaneous UV-Spectrophotometric methods for the estimation of Atenolol and Nifedipine in solid dosage forms. Ind J Pharm Sci 2005, 67:752-754.

38. Hemmateenejada B, Miri R, Kamali R: A Kinetic spectrophotometric method for determination of amlodipine and Nifedipine in pharmaceutical preparations. J Iran Chem Soc 2009, 6:113-120.

39. Rahman N, Najmul S, Azmi H: New spectrophotometric methods for the determination of nifedipine in pharmaceutical formulations. Acta Biochim Pol 2005, 52:915-922.

40. Sastry CSP, Chintalapati R, Venkateswarlu R: A simple spectrophotometric method for estimation of nifedipine. J Inst Chem 1997, 69:187.

41. Revathi R, Ethiraj T, Saravanan VS, Ganeshan V, Saranya V, Sengottuvel T: New spectrophotometric determination of nifedipine using hydrotropic solubilization. Int J Pharm Pharm Sci 2010, 2:74-76,

42. Segun AA, Olajire AA, Olakunle SI: A new colorimetric method for thedetermination of nifedipine tablets by derivatization using 4-carboxyl 2,6dinitrobenzene diazonium ion. Int J Ind Chem 2012, 3:1-8.

43. Yritia M, Parra P, Igelisias E, Barbanoj JM: Quantitation of nifedipine inhuman plasma by on-line solid-phase extraction and highperformanceliquid chromatography. J Chromatog A 2000, 870:115-119.

44. Zendelovska D, Simeska S, Sibinovska O, Kostova E, Milosevska K, Jakovski K, Jovanovska E, Kikerkov I, Trojacanec J, Zafirov D: Development of an HPLC method for the determination of nifedipine in human plasma by solid-phase extraction. J Chromatogr B Analyt Technol Biomed Life Sci 2006, 24(839):85-88.

45. Awad Uday Y, Shravan Kumar P, Dinesh Kumar A, Bari S: Estimation of nifedipine by reverse phase high performance liquid chromatography tablet dosage form. Int. J. of Pharm. \& Life Sci 2011, 2:610-612.

46. Ahmad M, Ahmad T, Sultan RA, Murtaza G: Pharmacokinetic Study ofNifedipine in Healthy Adult Male Human Volunteers. Trop J Pharm Res 2009, 8(5):385-391

47. Mahmood A, Tasneem A, Rafi AS, Jamal K, Ghulam M: Bioavailability andpharamcotherapeutics of nifedipine in human after single oral dose administration. Acta Pharmaceutica Sciencia 2010, 52:45-54.

48. Patravale VB, Nair VB, Gore SP: High performance thin layer chromatographic determination of nifedipine from bulk drug and from pharmaceuticals. J Pharm Biomed Anal 2000, 23:623-627.

49. Bretnall AE, Clarke GS: Investigation and optimisation of the use of micellar electrokinetic chromatography for the analysis of six cardiovascular drugs. J Chromatogr A 1995, 700:173-178.

50. Dumitrescu V, David V, Pavel A: Polarographic determination of nifedipine and chloramphinicol. Rev Chim 2001, 52:317-320.

51. Ghoneim MM, Tawfik A, Khashaba PY: Cathodic adsorptive stripping square-wave voltammertic detetermination of nifedipine drug in bulk, pharmaceutical formulation and human serum. Anal Bioanal Chem 2003, 375:369-375.

52. Richter P, Toral MI, Quiroz G, Jaque P: Flow-through polarographic cell for flow-injection analysis determination of nifedipine in pharmaceutical formulations. Lab Rob Autom 1997, 9:255-262.

53. Streel B, Zimmer C, Sibernaler R, Ceccato A: Simultaneous determination of nifedipine and dehydronifedipine in human plasma by liquid chromatography-tandem mass spectrometry. J Chromatogr B Biomed Sci Appl 1998, 720:119-128.

54. Srinivas R, lqbal A, Nirmala N, Saral T, Arindam M: Estimation of nifedipine in human plasma by LC/MS/MS. Asian J Pharm Clin Res 2013, 6:83-86.
55. Food and Drug Administration (FDA): Guidance for Industry Food- Effect bio Availability and Fed Bio Equivalence Studies. USA: U.S. Department of Health and Human services Food and Drug Administration Centre for Drug Evaluation and research (CDER); 2002.

56. Food and Drug Administration (FDA): Guidance for Industry Bio Availability and Fed Bio Equivalence Studies for Orally Administered Drug Products-General Considerations. USA: U.S. Department of Health and Human services Food and Drug Administration Centre for Drug Evaluation and research (CDER); 2003.

57. ICH Guideline, Q2(R1): Validation of Analytical Procedure. London: Text and Methodology London; 2005.

doi:10.1186/1752-153X-8-17

Cite this article as: Ezzeldin et al:: Development and validation of LC/ MS/MS method for the simultaneous determination of montelukast, gliclazide, and nifedipine and its application to a pharmacokinetic study. Chemistry Central Journal 2014 8:17.

Publish with ChemistryCentral and every
scientist can read your work free of charge
"Open access provides opportunities to our
colleagues in other parts of the globe, by allowing
anyone to view the content free of charge."
W. Jeffery Hurst, The Hershey Company.
- available free of charge to the entire scientific community
- peer reviewed and published immediately upon acceptance
- cited in PubMed and archived on PubMed Central
- yours - you keep the copyright
Submit your manuscript here:
http://www.chemistrycentral.com/manuscript/

